\title{
Manifiesto a favor de lo inútil
}

H. Ortega

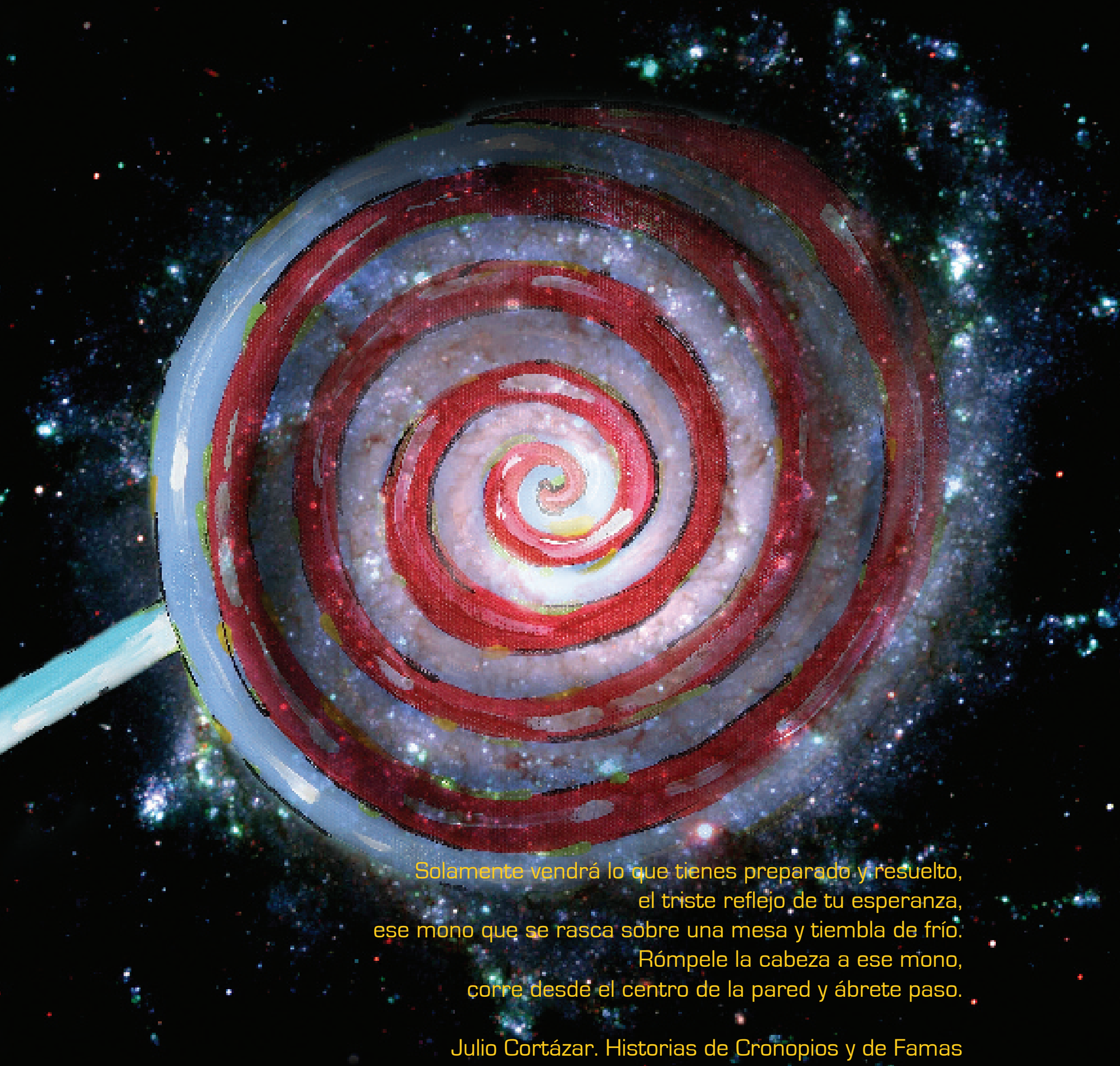


Hace unos cuantos años tuve la oportunidad de conocer a un físico del famoso Max-Planck-Institut de Dortmund, Alemania, quién había venido de paseo al Ecuador. Empiezo hablando de su vínculo con ese prestigioso instituto de investigación europeo, porque de lo contrario nadie se interesaría por mi artículo y pasaría de inmediato a cosas más serias y prácticas.

Como buen científico, este excéntrico personaje -Mario Markus era su nombretomaba como única motivación para realizar sus actividades su característica lúdica podemos decir que vivía su vida jugando-. Entre otras cosas, escribía literatura -de hecho, realizó un recital de poesía en la Casa de la Cultura-; viajaba por el mundo conociendo culturas nuevas -se había adentrado, por ejemplo, en la selva ecuatoriana para descubrir los seductores secretos de la ayahuasca-; y en sus ratos libres trabajaba haciendo investigación en física.

Sus campos de investigación, por supuesto, tampoco eran muy serios que digamos: los patrones que dibuja el café al ser mezclado en la leche, la razón de las formas que aparecen pintadas por la naturaleza en las conchas de ciertos moluscos marinos, el comportamiento de los granitos de arena ubicados sobre un parlante que vibra, la manera en que se distribuyen pelotitas diferentes ubicadas sobre un disco en rotación, etc. $Y$ entre todas esas rarezas: los monos.

Para entender cómo es que se produce la cerveza bajo la acción de las células de levadura (o, más exactamente, de sus enzimas, que transforman la glucosa en alcohol) el doctor Markus había utilizado gráficos matemáticos -muy socorridos cuando se estudian sistemas dinámicos caóticos- y obtuvo para su sorpresa ciertos patrones que le resultaron estéticos. Jugando con los parámetros involucrados, variándolos imaginativamente, fue encontrando más y más de estos gráficos estéticos, que él denominó "monos". La producción de monos fue tan profusa e interesante que incluso se llegó a organizar algunas exposiciones con ellos.

Usted quizá se esté preguntando, querido lector de una revista de ingeniería, cómo es posible que en un país tan desarrollado como Alemania, un instituto tan serio como el Max Planck se preste para financiar los juegos de semejante tipo. La respuesta es simple: la historia le ha mostrado que hacerlo es conveniente.

Así es, la Historia de la Ciencia está llena de personajes que vivieron como el doctor Markus: jugando. ¿Qué hacían sino jugar aquellos que investigaron cosas tan inútiles como unas bolitas cargadas de un algo misterioso y fascinante que llamaban "electricidad", por ejemplo? ¡Y ahora la electricidad mueve al mundo! De este tipo de ejemplos los países desarrollados aprendieron hace mucho tiempo esta lección, como es casi imposible prever las posibles consecuencias prácticas de las investigaciones de los científicos, es necesario apoyar éstas sin importar lo inútiles que parezcan. Es una lección dura que, por otra parte, nosotros como Tercer Mundo aún no aprendemos.

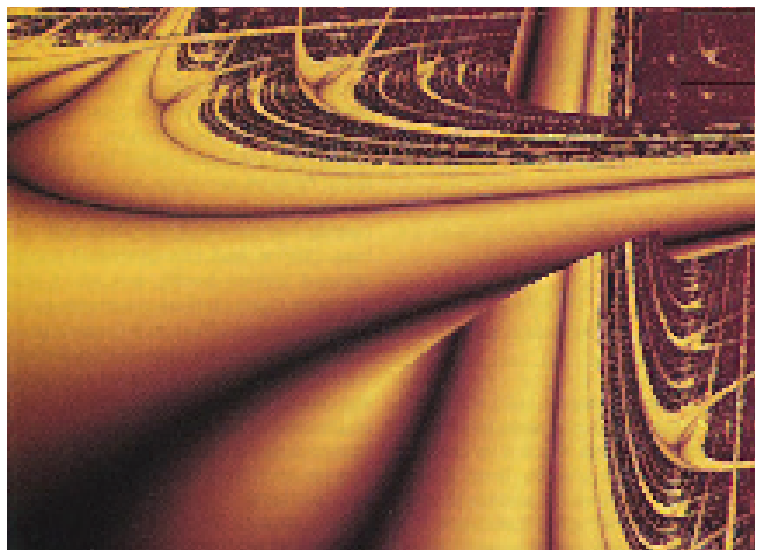

Enfermos de la mentalidad ultra-pragmática de la era tecnológica en la que vivimos, aquejados por necesidades urgentes y apremiantes, tendemos a dar la espalda al quehacer que no prometa ventajas prácticas inmediatas; inmersos en el culto a la imagen y la forma, tendemos a despreciar todo aquello que no se haga en un laboratorio con fachada seria. Sin saberlo, vamos inclusive en contra de nuestra misma conveniencia. ¿Por qué no romper esos arquetipos? ¿Por qué no retornar a lo simple, también en el ámbito de la ciencia? Retornar a lo sencillo, hacer las cosas por la simple fascinación ante el misterio, por el simple gusto de descubrir. Por romperle la cabeza al corrosivo y triste mono de lo cotidiano. 


\section{PROPUESTA}

Creo que podemos empezar desde nuestros espacios de difusión. Las aulas pueden ser -lo digo por experiencia propia- caldo de cultivo, donde de vez en cuando surgen preguntas $\mathrm{o}$ inquietudes interesantes, curiosidades, dudas; semillas del auténtico conocimiento científico. ¿Por qué volver la espalda a esas semillas y a las plantas -pequeñas o grandes, quién sabe- que de allí pueden surgir? ¿Por qué despreciar eso como si no nos hiciera falta?

Mi propuesta es entonces que se abra una sección en nuestra revista de ingeniería destinada a mostrar esos pequeños, cotidianos y quizá inútiles juegos del intelecto de nuestros estudiantes, o de nosotros mismos como docentes. A continuación, como ejemplo, pongo a consideración de usted, amable lector, uno de esos juegos que mis estudiantes han realizado.

\section{TRAYECTORIAS ORTOGONALES Y ESTÉTICA}

Una de las aplicaciones de las ecuaciones diferenciales de primer orden que estudiamos como parte de esta materia son las trayectorias ortogonales. El problema es simple: dada una función de la forma

$$
f(x, y)=C
$$

encontrar la ecuación de las llamadas "trayectorias ortogonales". Como puede verse fácilmente, la gráfica de la ecuación (1) no es una sola curva, sino un conjunto infinito de curvas que denominamos "familia de curvas". Las trayectorias ortogonales, entonces, no son más que un conjunto de curvas perpendiculares a todas y cada una de las curvas de la familia original.

Sin título. Mauricio Punina
El problema se resuelve bastante simplemente utilizando ecuaciones diferenciales, y de ahí podría no pasar la cosa. Sin embargo, inspirado por el trabajo del doctor Markus sobre los monos, se me ocurrió que sería posible sacarle un poquito más de jugo a este sencillo tema. ¿Qué tal si graficásemos, con ayuda de una computadora, las familias de curvas y sus trayectorias ortogonales, variando creativamente los valores de las constantes y dando colores a las curvas? Propuse este trabajo a mis estudiantes, obteniendo algunos resultados bastante interesantes, que presento ahora a ustedes. ¡Disfrútenlo!

Las gráficas no muestran exactamente una perpendicularidad entre las familias originales y sus trayectorias ortogonales; esto es debido a la diferencia de escalas entre los ejes $x$ e $y$. Es precisamente este "defecto" en las gráficas el que por otra parte crea una interesante sensación de tridimensionalidad.

Invitamos al lector a que cree sus propias gráficas de trayectorias ortogonales. Por el simple gusto de ver surgir en su pantalla estas extrañas representaciones de mundos oníricos o futuristas...

Sin título. Alejandro Santamaría
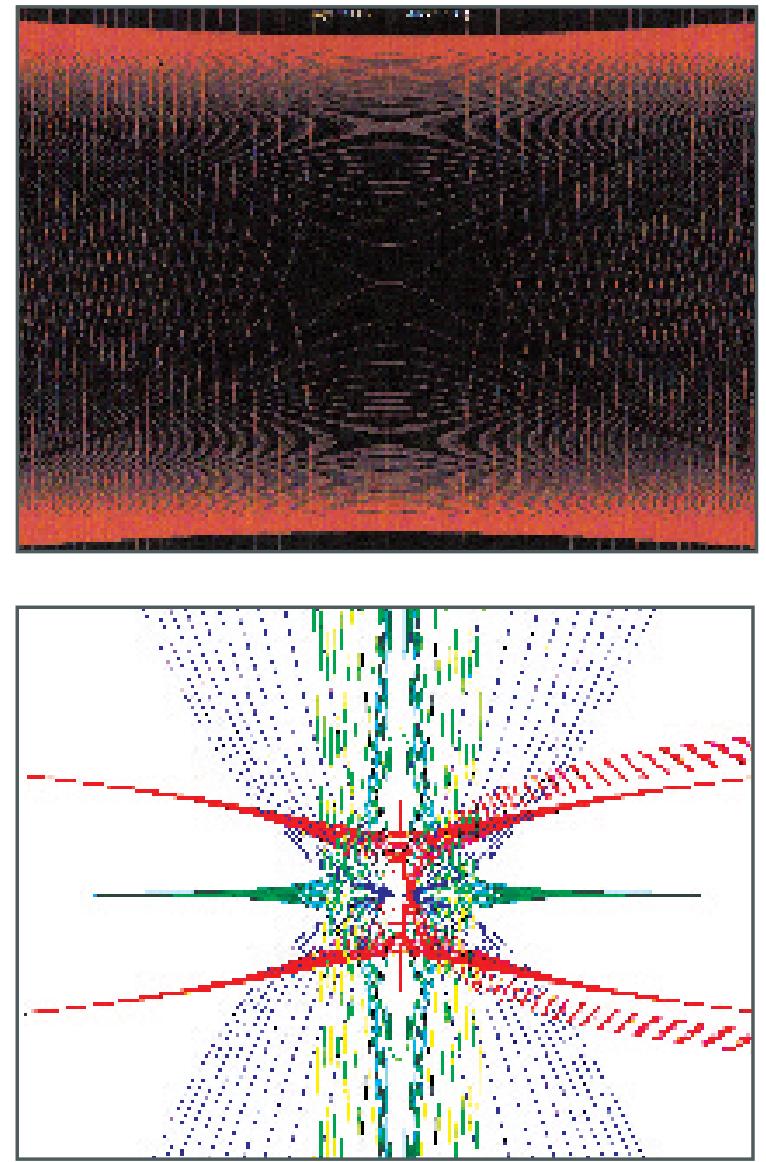